\title{
EFFECT OF OVEN AND MICROWAVE DRYING ON POLYPHENOLS CONTENT AND ANTIOXIDANT CAPACITY OF HERBAL TEA FROM STROBILANTHES CRISPUS LEAVES
}

\begin{abstract}
NUR FATIMAH LASANO ${ }^{1,2}$, ASMAH RAHMAT ${ }^{3}$, NURUL SHAZINI RAMLI ${ }^{2}$, MOHD FADZELLY ABU BAKAR ${ }^{3,4 *}$
${ }^{1}$ Department of Nutrition and Dietetics, Faculty of Medicine and Health Sciences, Universiti Putra Malaysia, 43400 Serdang, Selangor, Malaysia. ${ }^{2}$ Department of Food Science, Faculty of Food Science and Technology, Universiti Putra Malaysia, 43400 Serdang, Selangor, Malaysia. ${ }^{3}$ Department of Technology and Natural Resources, Faculty of Applied Sciences and Technology, Universiti Tun Hussein Onn Malaysia, Hab Pendidikan Tinggi Pagoh, KM 1, Jalan Panchor, 84600 Muar, Johor, Malaysia. ${ }^{4}$ Centre of Research for Sustainable Uses of Natural Resources, Universiti Tun Hussein Onn Malaysia, 86400 Parit Raja, Batu Pahat, Johor, Malaysia. Email: fadzelly@uthm.edu.my
\end{abstract}

Received: 08 January 2018, Revised and Accepted: 23 March 2018

ABSTRACT

Objective: This study aimed to evaluate the effect of oven and microwave drying on total phenolic content (TPC), total flavonoid content (TFC), and antioxidant capacity of unfermented and fermented tea developed from Strobilanthes crispus leaves.

Methods: TPC and TFC were estimated using a spectrophotometric method, while antioxidant capacity was determined using ferric reducing antioxidant power assay and 2,2-diphenyl-1-picrylhydrazyl radical scavenging assay. Camellia sinensis (tea plant), that is, used for the production of all varieties of commercial tea and fresh S. crispus leaves were served as controls in this study.

Results: The highest antioxidant activity and TPC were observed in S. crispus tea developed from microwave-dried leaves, while the highest TFC was observed in oven-dried tea. Unfermented $S$. crispus tea showed significantly higher values $(\mathrm{p}<0.05)$ for antioxidant activity, TPC, and TFC as compared to fermented S. crispus tea. A strong and moderate correlation was observed between antioxidant activity and TPC as well as TFC values.

Conclusion: The present work clearly showed that S. crispus tea developed from microwave-dried leaves able to preserve the polyphenols and hence contribute to excellent antioxidant capacity. Incorporation of unfermented S. crispus tea in the diet can be a good source of natural antioxidant.

Keywords: Green tea, Black tea, Total phenolic, Total flavonoid, 2,2-diphenyl-1-picrylhydrazyl, Ferric reducing antioxidant power assay.

(c) 2018 The Authors. Published by Innovare Academic Sciences Pvt Ltd. This is an open access article under the CC BY license (http://creativecommons. org/licenses/by/4. 0/) DOI: http://dx.doi.org/10.22159/ajpcr.2018.v11i6.24660

\section{INTRODUCTION}

Tea is one of the most widely consumed beverages in the world since ancient time. It was manufactured from the young leaves of the true tea plant, Camellia sinensis [1]. Tea can be found in different forms, depending on the fermentation and preparation methods, for example, black (fermented), green (unfermented), and oolong (semi-fermented) tea [2]. Numerous researches have shown the effectiveness of tea as the preventive agent for toxic chemicals and carcinogens [3,4]. Tea polyphenols are mostly recognized for their antioxidant activities, arising from their ability to scavenge reactive oxygen species $[5,6]$. The polyphenols bind to metal ions, preventing them from participating in peroxidative reactions [3]. Therefore, tea polyphenols appeared to be associated with reduced risk of cardiovascular diseases (CVD) and cancer as proven by in vitro and in vivo studies [4]. Recently, many researchers have focused their investigation on developing herbal teas from potential plants other than C. sinensis [7].

Strobilanthes crispus (L.) Bremek is known locally as "pecah kaca" or "jin batu" in Malaysia or "daun picah beling" in Jakarta. It is local to nations from Madagascar to Indonesia and Malaysia [8]. S. crispus contain different phytochemical groups, including polyphenols, alkaloids, vitamins, and minerals [9]. The mixture of these compounds may exert a positive impact on the chronic diseases such as hypertension, CVD, and cancer $[9,10]$. Numerous researches have been conducted on the bioactivity of ethanolic extract of $S$. crispus herbal tea, and it has been shown that it possesses anticancer, antidiabetic [11], and antibacterial properties [12].

Tea manufacturing processes involved withering, steaming, blending, and drying $[7,13]$. These processes can exert a strong impact on the stability of the bioactive compounds, especially the polyphenols. Drying, specifically act as a preservation method, where the function is to lower the water activity to inhibit the growth of microorganisms [14]. However, it is also involved in the enzymatic and non-enzymatic processes that may lead to significant changes in the composition of phytochemicals in the plants [15].

Drying can be performed by traditional sun drying or conventional oven drying [16]. Various researches have reported that these drying methods can bring adverse effects to the antioxidant activity of the plant products [17-20]. Meanwhile, microwave technology has been considered as the best drying method for food products due to uniform drying and better quality of the products [21]. Microwave drying may exert little or no significant losses or enhancement in antioxidant properties compared to the oven drying method [7]. These two methods (microwave and oven drying) can be easily performed to produce herbal tea in the domestic setting. However, to the best of the author's knowledge, there is limited information available on the effect of microwave drying on the polyphenols content of unfermented and fermented tea. Therefore, this study was conducted to evaluate the effect of microwave and convection oven drying on total phenolic content (TPC), total flavonoid content (TFC), and antioxidant capacity of unfermented and fermented S. crispus tea.

\section{METHODS}

Materials

All reagents and chemical used were analytical grade: Absolute ethanol (Merk, Darmstadt, Germany), Folin-Ciocalteu reagent (Merk, Darmstadt, Germany), sodium bicarbonate (Merk, Darmstadt, Germany), aluminum chloride (Merk, Darmstadt, Germany), potassium 
acetate (Merk, Darmstadt, Germany), gallic acid (Sigma Chemical Co., St Louis, MO, USA), quercetin (Sigma Chemical Co., St Louis, MO, USA), butylated hydroxytoluene (BHT) (Sigma Chemical Co., St Louis, MO, USA), and 2,2-diphenyl-1-picryl-hydrazyl (DPPH) (Sigma Chemical Co., St Louis, MO, USA).

\section{Sample preparation}

The fresh leaves of S. crispus were collected from Sg. Ramal, Selangor, Malaysia. The young leaves were selected from the plants (the apex of the $5^{\text {th }}$ leaf). Then, the leaves were washed thoroughly with tap water and rinsed with distilled water. The commercial green tea $(C$. sinensis, Premium) was purchased from the market and used as a control. All the samples were stored at $-20^{\circ} \mathrm{C}$ until extraction and analysis.

\section{Preparation of unfermented S. crispus tea}

The preparation of unfermented S. crispus tea was based on the preparation of $C$. sinensis green tea as described by Rasmussen and Rhinehart [13]. The method consists of four steps which are withering, steaming, blending, and drying. In the drying process, two methods were used: Convection oven and microwave drying. In the convection oven drying, the sample was dried for $10 \mathrm{~min}$ at $95^{\circ} \mathrm{C}-100^{\circ} \mathrm{C}$ or until dry. While for microwave drying, the sample was spread on the tray in a standard domestic microwave oven (Samsung $900 \mathrm{~W}$ ). The leaves were dried at $900 \mathrm{~W}$ for $2 \mathrm{~min}[22]$.

\section{Preparation of fermented S. crispus tea}

The preparation of fermented $S$. crispus tea was based on the preparation of Camellia theifera black tea as described by Adisewojo [23]. The method consists of four steps which include withering, rolling/blending, fermentation, and drying. In the drying process, convection oven and microwave drying methods were used as previously mentioned in the preparation of unfermented S. crispus tea.

\section{Sample extraction}

The extraction of all types of tea was based on the method by Gadow et al. [24]. Two grams of the sample was extracted by pouring boiling distilled water $(40 \mathrm{ml})$ into the beaker containing the tea. The solution was mixed by stirring with a wire shaker for $30 \mathrm{~min}$ and then centrifuged for $10 \mathrm{~min}$ at $40 \mathrm{rpm}$. The mixture was allowed to cool and subsequently filtered. The filtrate was used for determination of TPC, TFC, and antioxidant capacity. Three replications were done for each analysis $(\mathrm{n}=3)$.

\section{Determination of TPC}

The Folin-Ciocalteau assay was used to determine the TPC as described by Velioglu et al. [25]. The Folin-Ciocalteau reagent was diluted 10-fold with distilled water. Then, $2.25 \mathrm{ml}$ of Folin-Ciocalteau reagent solution was mixed with $300 \mu \mathrm{l}$ of extract. The solution was mixed using vortex and then allowed to stand for $5 \mathrm{~min}$ at room temperature $\left(24^{\circ} \mathrm{C}\right)$, followed by the addition of $2.25 \mathrm{ml}$ of sodium bicarbonate $(60 \mathrm{~g} / \mathrm{l})$ solution to the mixture. The mixture was incubated for $90 \mathrm{~min}$ at room temperature $\left(24^{\circ} \mathrm{C}\right)$. Triplicate measurements were carried out and the absorbance was measured at $725 \mathrm{~nm}$ using a spectrophotometer. TPC was quantified using a calibration curve obtained by measuring the absorbance of the known concentrations of gallic acid solutions. The results were calculated as gallic acid equivalent (GAE)/g of dry extract.

\section{Determination of TFC}

TFC was determined according to the aluminum chloride colorimetric method as described by Ling and Tang [26]. About $0.1 \mathrm{ml}$ of $10 \%$ aluminum chloride and $0.1 \mathrm{ml}$ of $1 \mathrm{~mol} / \mathrm{l}$ potassium acetate was mixed with the tea extract $(0.5 \mathrm{ml})$, ethanol $(1.5 \mathrm{ml})$, and distilled water $(2.8 \mathrm{ml})$. After $40 \mathrm{~min}$ of incubation at room temperature $\left(24^{\circ} \mathrm{C}\right)$, the absorbance was measured using a spectrophotometer at $415 \mathrm{~nm}$. Quercetin was used as a standard (the concentration range: 0.015$0.9 \mathrm{mg} / \mathrm{ml}$ ) and the flavonoid content was expressed as milligram $\mathrm{QE} / \mathrm{g}$ of dry extract. Analysis of sample extract and standard were conducted in triplicate $(\mathrm{n}=3)$.

\section{Determination of antioxidant capacity}

\section{DPPH free radical scavenging assay}

DPPH free radical scavenging assay was done according to the method by Nurul and Asmah [27]. An aliquot of $400 \mu \mathrm{l}$ of samples or control (distilled water) or BHT ( $50 \mathrm{mg} / \mathrm{l}$ and $200 \mathrm{mg} / \mathrm{l}$ ) was mixed with $1600 \mu \mathrm{l}$ of tris-HCI buffer. The mixture was then added to $2 \mathrm{ml}$ of $500 \mu \mathrm{mol}$ DPPH in absolute ethanol. The mixture was shaken vigorously and allowed to stand at room temperature $\left(24^{\circ} \mathrm{C}\right)$ for $20 \mathrm{~min}$ in the dark. The mixture was measured using a spectrophotometer at $517 \mathrm{~nm}$ using ethanol (100\%) and DPPH as blank. The analysis was performed in triplicate for sample extract and standard. The free radical scavenging activity was calculated using the formula below:

Scavenging effect $(\%)=1-\frac{\text { absorbance of sample }}{\text { absorbance of control }} \times 100$

\section{Ferric reducing antioxidant power (FRAP) assay}

FRAP assay was determined using the method from Benzie and Strain [28]. The working FRAP reagent was prepared by mixing $300 \mathrm{mM}$ acetate buffer ( $\mathrm{pH}$ 3.6), $10 \mathrm{mM} \mathrm{2,} \mathrm{4,} 6$-trispyridyl-s-triazine solution, and $20 \mathrm{mM} \mathrm{FeCl}_{3} .6 \mathrm{H}_{2} \mathrm{O}$ in a 10:1:1 ratio before use. Then, the FRAP reagent was heated at $37^{\circ} \mathrm{C}$ in water bath for $10 \mathrm{~min}$. After that, $3 \mathrm{ml}$ of FRAP reagent was added into the cuvette and blank reading was taken at $593 \mathrm{~nm}$ using a spectrophotometer. A total of $100 \mu \mathrm{l}$ sample extract and $300 \mu \mathrm{l}$ distilled water was added to the test tubes. The mixture was incubated for $4 \mathrm{~min}$ and the second absorbance reading was performed at $593 \mathrm{~nm}$. The FRAP values were determined by the change in the absorbance value after $4 \mathrm{~min}$ from the initial blank reading. Standards of known Fe sulfate (ferrous sulfate heptahydrate) concentrations were prepared using several concentrations from 1 to $10 \mathrm{mM}$. FRAP value was expressed as $\mu \mathrm{mol}$ of ferrous equivalent/g of dry extract.

\section{Statistical analysis}

All analyses were performed using MINITAB version 16. The experimental results were reported as a mean \pm standard deviation. Analysis of variance (ANOVA) with a post hoc test (Fisher) was used to determine the significance of differences for multiple comparisons at $\mathrm{p}<0.05$. The Pearson's correlation coefficient $(r)$ was used to determine the correlation between total phenolic and TFC and antioxidant activity DPPH free radical scavenging assay and FRAP assay). Differences at $\mathrm{p}<0.05$ were considered statistically significant.

\section{RESULTS AND DISCUSSION}

We investigated the antioxidant components (TPC and TFC) and antioxidant capacity of $S$. crispus herbal tea. In this work, two types of tea (unfermented and fermented) were developed from S. crispus leaves that were dried using microwave and oven drying method. As previously discussed, the procedures chosen to dry the sample may result in the retention of most of its biofunctional components or otherwise, the procedures may cause a significant loss of the bioactive compounds [27]. The S. crispus leaves were dried using the selected methods and extracted using hot boiling water extraction to mimic the household preparation and brewing conditions of herbal tea [29].

\section{TPC and TFC}

The TPC and TFC of the samples were presented in Table 1. TPC was expressed as mg GAE/g of dry extract, while TFC were expressed as $\mathrm{mg} \mathrm{QE} / \mathrm{g}$ of dry extract. S. crispus tea was compared to controls and results showed that $S$. crispus tea had significantly lower TPC than the green tea (C. sinensis, Premium). Microwave-dried unfermented tea had the highest TPC (41.94 mg GAE/g) followed by oven-dried unfermented tea (24.68 mg GAE/g); microwave-dried fermented tea (15.96 mg GAE/g) and oven-dried fermented S. crispus tea $(6.53 \mathrm{mg}$ GAE/g) (Table 1).

Similarly, the previous study had reported the same trend of TPC in S. crispus, but with lower values [11]. The difference results obtained from the previous study may be attributed to the variation of TPC with 
the different climate, season, horticulture practices [30], or the storage condition and the time gap before the samples being analyzed [27]. The largest component in phenolic compounds is flavonoid. In the present study, the estimation of TFC was based on the reaction between aluminum trichloride and the hydroxyl group of flavones and flavonols as well as ortho-dihydroxyl groups of flavonoids [31]. The reactions lead to color development that can be measured using a spectrophotometer.

Table 1 showed the highest TFC was observed in the commercial green tea (C. sinensis, Premium) $(86.51 \pm 11.80 \mathrm{mg} \mathrm{QE} / \mathrm{g}$ followed by unfermented S. crispus tea, fermented S. crispus tea, and fresh S. crispus leaves. Analysis from one-way ANOVA showed that the TPC and TFC of unfermented $S$. crispus tea were significantly higher $(\mathrm{p}<0.05)$ than fermented S. crispus tea (Table 1). This result may be explained by the fact that the oxidation of polyphenols during the fermentation stage contribute to lower quality of the food product [32]. Hence, fermented tea had lower polyphenol content than that of unfermented tea. Besides, heat treatment (steaming) was applied during the production of unfermented tea, causing deactivation of the enzyme that catalyzes their oxidative polymerization. Thus, it prevented the tea polyphenols from being damaged during the process [33]. On the other hand, the fermented tea had undergone a fermentation step which caused the disruption of the leaf cells and promotes enzymatic oxidation of the flavanols to produce polymeric flavonoids [34].

Microwave-dried unfermented S. cripus tea had significantly higher TPC $(\mathrm{p}<0.05)$ as compared to oven-dried S. cripus tea (Table 1$)$. These results confirm the findings of Valadez-Carmona et al. [35] who found higher retention of phenolic compounds in microwave-dried Cocos nucifera as compared to oven-dried sample. During microwave drying, the heat generated from the microwave has high energy and able to inactivate the degradative enzymes at much faster rate than the conventional techniques [36]. The plant tissues were also destroyed after microwave drying causes the release of bound phenolic compounds [14]. Besides, the moisture content in the sample plays a significant role in antioxidant and bioactive components analysis as its influence the penetration of solvent and chemicals into the food matrix. Ismail et al. [9] found that the moisture content of fresh $S$. crispus leaves was $69.3 \pm 0.1 \%$, while microwave and oven drying decreased the moisture content in the range of $8.5-4.4 \%$, respectively [35]. As shown in Table 1, fresh S. crispus leaves and fermented S. crispus tea prepared using oven-dried leaves had the lowest TPC $(6.53 \pm 2.53$ and $6.58 \pm 1.80$ respectively). Similarly, Chan et al. [37] reported a significant decrease in the TPC of ginger leaves after sun- and oven-drying. During microwave drying, the moisture evaporated at higher rate which could be due to the increase in internal temperature and greater vapor pressure gradient [38]. These conditions assisted the released of bioactive components from the samples. Thus, microwave drying improves the final quality of S. cripus tea at a shorter drying period.

On the other hand, statistical analysis showed there was no significant difference in TFC between microwave-dried and oven-dried for both types of $S$. crispus tea $(\mathrm{p}>0.05)$ (Table 1$)$. It is important to note that the chemical changes that occur after drying are due to the complex mechanism [39]. Therefore, it is always challenging to forecast the changes even though both phenolic and flavonoid compounds are affected by food processing [40]. The type of polyphenols and their location in the plant cells may also influence the increase or decrease of TPC and TFC after the drying process [39]. For instance, the major polyphenolic compounds in $C$. sinensis are the flavan-3-ols called catechin [41] while the major flavonoid compound in $S$. crispus is quercetin [9].

\section{Antioxidant capacity}

\section{DPPH free-radical scavenging assay}

The antioxidant activity of the samples was assessed using DPPH free radical scavenging activity and the values were compared to synthetic antioxidant, BHT, and commercial green tea (C. sinensis, Premium). The value of free radical scavenging activity (\%) was corresponded to antioxidant activity of the sample. As can be seen from Table 2, $200 \mathrm{mg} / \mathrm{l}$ BHT had the highest radical scavenging activity $(74.42 \pm 2.50 \%)$ followed by the commercial green tea $(65.43 \pm 0.31 \%)$, unfermented S. crispus tea $(61.17 \pm 0.74 \%$ and $58.27 \pm 0.48 \%$ for microwave-dried and oven-dried leaves, respectively), fresh $S$. crispus leaves and fermented S. crispus tea $(\mathrm{p}<0.05)$ (Table 2). Microwave drying of the leaves displayed higher radical scavenging activity than oven drying method $(\mathrm{p}<0.05)$. Fresh $S$. crispus leaves showed similar radical scavenging activity with BHT at $50 \mathrm{mg} / \mathrm{l}(51.73 \pm 3.36$ and $48.39 \pm 0.62$ respectively) (p>0.05) (Table 2).

The data from the present study were consistent with those of MohdFadzelly et al. [11] who found that the unfermented tea had higher antioxidant activity compared to fermented tea. Another study by Muslim et al. [42] who investigated the antioxidant activity of methanolic and aqueous extracts of $S$. crispus leaves using DPPH free radical scavenging assay showed moderate antioxidant properties compared to controls which were evidenced by the quenching of the DPPH radicals. Gallic acid, quercetin, BHA, and ascorbic acid displayed potent DPPH free radical scavenging activity which produced $\mathrm{EC}_{50}$ values of 12.6, 15.3, 21.9 , and $25.5 \mu \mathrm{g} / \mathrm{ml}$, respectively. Similarly, Suhaila et al. [43] revealed that the aqueous extracts of $S$. crispus leaves had higher antioxidant activities compared to ethanolic extract. However, antioxidant activities of the extracts were considered to be lower than that of gallic acid. The difference values obtained from the previous study may be attributed to different sample preparation and extraction method.

\section{FRAP assay}

For FRAP assay, a similar trend was observed, whereby the commercial green tea and unfermented S. crispus tea prepared using microwave-

Table 1: TPC and TFC of unfermented and fermented S. crispus tea

\begin{tabular}{lll}
\hline Sample & TPC $(\mathbf{m g ~ G A E} / \mathbf{g})$ & TFC $(\mathbf{m g}$ QE/g) \\
\hline Unfermented S. crispus tea & & \\
Microwave-dried & $41.94 \pm 16.96^{\mathrm{b}}$ & $34.68 \pm 1.08^{\mathrm{b}}$ \\
Oven-dried & $24.68 \pm 5.24^{\mathrm{c}}$ & $36.00 \pm 2.31^{\mathrm{b}}$ \\
Fermented S. crispus tea & & \\
Microwave-dried & $15.96 \pm 4.32^{\mathrm{c}}$ & $22.43 \pm 1.09^{\mathrm{c}}$ \\
Oven-dried & $6.53 \pm 2.53^{\mathrm{d}}$ & $21.52 \pm 1.78^{\mathrm{c}}$ \\
Green tea & $228.48 \pm 4.86^{\mathrm{a}}$ & $86.51 \pm 11.80^{\mathrm{a}}$ \\
$\begin{array}{l}\text { (C. } \text { sinensis, Premium) } \\
\text { Fresh S. crispus leaves }\end{array}$ & $6.58 \pm 1.80^{\mathrm{d}}$ & $1.14 \pm 0.08^{\mathrm{d}}$ \\
\hline Results are presented as mean $\pm \mathrm{SD}(\mathrm{n}=3)$. For each column, values followed \\
by the different letters in superscripts (a-d) are statistically different at $P<0.05$. \\
SD: Standard deviation, TPC: Total phenolic content, TFC: Total flavonoid \\
content, S. crispus: Strobilanthes crispus, C. sinensis: Camellia sinensis, GAE: Gallic \\
acid equivalent
\end{tabular}

Table 2: DPPH free radical scavenging activity of unfermented and fermented $S$. crispus tea

\begin{tabular}{ll}
\hline Sample & $\begin{array}{l}\text { DPPH free radical scavenging } \\
\text { activity (\%) }\end{array}$ \\
\hline Unfermented S. crispus tea & \\
$\quad$ Microwave-dried & $61.17 \pm 0.74^{\mathrm{b}}$ \\
Oven-dried & $58.27 \pm 0.48^{\mathrm{c}}$ \\
Fermented S. crispus tea & $30.50 \pm 4.52^{\mathrm{e}}$ \\
$\quad$ Microwave-dried & $15.44 \pm 0.39^{\mathrm{f}}$ \\
Oven-dried & $65.43 \pm 0.31^{\mathrm{b}}$ \\
Green tea (C. sinensis, Premium) & $51.73 \pm 3.36^{\mathrm{d}}$ \\
Fresh S. crispus leaves & $48.39 \pm 0.62^{\mathrm{d}}$ \\
BHT $50 \mathrm{mg} / \mathrm{l}$ & $74.42 \pm 2.50^{\mathrm{a}}$ \\
BHT $200 \mathrm{mg} / \mathrm{l}$ &
\end{tabular}

DPPH: 2,2-diphenyl-1-picrylhydrazyl free radical scavenging assay. Results are presented as mean $\pm \mathrm{SD}(\mathrm{n}=3)$. For each column, values followed by different letters in superscripts $\left({ }^{\mathrm{a}-\mathrm{f}}\right)$ are statistically different at $P<0.05$. S. crispus: Strobilanthes crispus, C. sinensis: Camellia sinensis, BHT: Butylated hydroxytoluene 
dried leaves had the highest antioxidant activity (Table 3). Then, it was followed by oven-dried unfermented $S$. crispus tea and fermented $S$. crispus tea, while fresh $S$. crispus leaves showed the lowest antioxidant activity $(\mathrm{p}<0.05)$ (Table 3). ANOVA showed that microwave-dried leaves had significantly higher $(\mathrm{p}<0.05)$ FRAP values compared to oven-dried leaves of unfermented $S$. crispus tea ( $>>0.05$ ) (Table 3).

In this study, the effect of drying methods on unfermented and fermented tea was investigated. Analysis showed that there were significant differences on antioxidant activity $(\mathrm{p}<0.05)$ assayed by DPPH and FRAP between microwave-dried and oven-dried leaves for unfermented but not in fermented $S$. crispus tea. These results are in agreement with Chan et al. [44] who reported that microwave-dried green tea showed outstanding DPPH (IC $0.015 \mathrm{mg} / \mathrm{ml}$; AEAC 26,213 mg AA/100g) and higher FRAP values (123.0 mg GAE/g) compared to other commercial green tea. This result indicated that there are increases in antioxidant activity of tea using microwave drying compared to the conventional oven drying. This may be attributed to higher retention of phenolic compounds. As previously discussed, the intense heat was generated in microwave drying from the volumetric heating where the microwave energy was absorbed directly and internally by the plants and then converted into heat $[45,46]$. This heat resulted in disruption of the plant cell wall polymers due to the production of high vapor pressure and temperature inside the plant tissues. Therefore, more phenolic could be released [47]. Meanwhile, the heat from hot air oven drying resulted in the vaporization of volatile compound that causes the loss of compound in the water vapor [48]. Besides, inefficient denaturation of enzyme makes the initial enzyme degradation of antioxidant compound, thus significantly decrease in antioxidant activity of oven drying [49].

Previously, Yen and Chen [50] found that the antioxidant activity in the tea extract decreased in the order of semi-fermented tea > unfermented tea $>$ fermented tea. Fermentation causes oxidation or heat exposure toward the phytochemicals such as flavonol glycosides, caffeine, saponin, and ascorbic acid [51]. This might lead to reduction of antioxidant activity during tea fermentation [52]. It may be inferred that increased in scavenging activity of fresh $S$. crispus leaves despite of lower phenolic compounds compared to fermented tea could be the result of the preservation of antioxidants vitamins such as ascorbic acid.

Correlation between TPC, TFC, and antioxidant capacity of samples using DPPH radical scavenging and FRAP assays

The correlations between the assays were analyzed using Pearson correlation coefficient and r-values were presented in Table 4. The antioxidant activity for both assays, TPC and TFC were significantly correlated to each other. The r-values were as follows: DPPH/FRAP $r=0.878$; TPC/DPPH r=0.551; TPC/FRAP r=0.809; TFC/DPPH r=0.640; TFC/FRAP $r=0.861$; and TFC/TPC $r=0.960$ (Table 4). This could be attributed to the similar mechanistic basis for DPPH and FRAP assays which is the transfer of electrons from the antioxidant to reduce the oxidant [53].

The results of the present study indicated that high antioxidant activity is associated with high phenolic and flavonoid content. These results are consistent with those of Sudha et al. [54] who reported that both phenolics and flavonoid are categorized as a potential antioxidant. The antioxidant activity of phenolic compound could be explained by its unique structure and a high tendency for metal chelation as well as their redox properties [55]. Phenolic compounds contain at least one aromatic ring (C6) that bears one or more hydroxyl groups. These allow them to act as reducing agents, hydrogen donators, and singlet oxygen quenchers $[56,57]$. Flavonoid compounds are considered to be the largest group of naturally occurring phenol and their antioxidant capacity are depending on the position of $\mathrm{OH}$ group [58]. Therefore, the antioxidant activity of plant extracts also comes from the presence of other antioxidant secondary metabolites, such as flavonoids, proanthocyanidins, anthocyanins, and not limited to phenolics content $[59,60]$.
Table 3: Antioxidant activity of unfermented and fermented S. crispus tea

\begin{tabular}{ll}
\hline Sample & FRAP value $(\mu \mathbf{m o l}$ FE/g of dry extract $)$ \\
\hline Unfermented & \\
S. crispus tea & \\
$\quad$ Microwave-dried & $7320.05 \pm 326.28^{\mathrm{b}}$ \\
$\quad$ Oven-dried & $6010.85 \pm 101.13^{\mathrm{c}}$ \\
Fermented S. crispus & \\
tea & \\
$\quad$ Microwave-dried & $2434.82 \pm 189.63^{\mathrm{d}}$ \\
$\quad$ Oven-dried & $2332.43 \pm 231.28^{\mathrm{d}}$ \\
Green tea & $9993.65 \pm 130.26^{\mathrm{a}}$ \\
(C. sinensis, Premium) & \\
Fresh $S$. crispus leaves & $1059 \pm 95.0^{\mathrm{e}}$ \\
\hline
\end{tabular}

FRAP: Ferric reducing antioxidant power assay. Results are presented as mean $\pm \mathrm{SD}(\mathrm{n}=3)$. For each column, values followed by different letters in superscripts $\left({ }^{\mathrm{a}-\mathrm{e}}\right)$ are statistically different at $P<0.05$. FE: Ferrous equivalent, SD: Standard deviation, $S$. crispus: Strobilanthes crispus, C. sinensis: Camellia sinensis

Table 4: Pearson's correlation coefficient of TPC and TFC of $S$. crispus tea with their antioxidant activities

\begin{tabular}{lllll}
\hline Analysis & DPPH assay & FRAP assay & TPC & TFC \\
\hline DPPH assay & 1 & & & \\
FRAP assay & $0.878^{* *}$ & 1 & & \\
TPC & $0.551^{*}$ & $0.809^{* *}$ & 1 & \\
TFC & $0.640^{* *}$ & $0.861^{* *}$ & $0.960^{* *}$ & 1 \\
\hline
\end{tabular}

** Correlation is significant at $P<0.01$, ${ }^{*}$ Correlation is significant at $P<0.05$. DPPH: 2,2-diphenyl-1-picrylhydrazyl free radical scavenging assay, FRAP: Ferric reducing antioxidant power assay, TPC: Total phenolic content, TFC: Total flavonoid content, S. crispus: Strobilanthes crispus

\section{CONCLUSION}

In conclusion, unfermented $S$. crispus tea exhibits excellent antioxidant activity and is a potential source of phenolic compounds. Microwave drying of $S$. crispus leaves produced the highest antioxidant activity and TPC compared to the oven-drying method. This suggested that microwave drying can be used as an alternative drying method due to successful extraction of phenolic compound and energy and time efficient as well as affordable for household use compared to the ovendrying method. However, the variation in drying conditions and moisture content may induce stresses inside food components and subsequently affect the biofunctional compounds in the food products. Other factors such as the economy and consumer preference and acceptability should also be considered. Therefore, further study to determine the optimum drying conditions and sensory quality parameters of the tea such as color, flavor, and fragrance should be carried out.

\section{ACKNOWLEDGMENT}

The authors would like to thank Universiti Putra Malaysia for providing infrastructural facilities to carry out this study as well as Universiti Tun Hussein Onn Malaysia (UTHM) vot E15501 for funding publication fee of this manuscript.

\section{AUTHORS CONTRIBUTION}

Nur Fatimah Lasano: Designed and conducted the experiments, prepared the manuscript. Asmah Rahmat: Designed the experiments and revised the manuscript. Nurul Shazini Ramli: Analyzed the data and prepared the manuscript. Mohd Fadzelly Abu Bakar: Designed the experiments and revised the manuscript. All authors have read and approved the final manuscript.

\section{CONFLICT OF INTERESTS}

All authors have none to declare. 


\section{REFERENCES}

1. Cabrera C, Giménez R, López MC. Determination of tea components with antioxidant activity. J Agric Food Chem 2003;51 Suppl 15:4427-35.

2. Astill C, Birch MR, Dacombe C, Humphrey PG, Martin PT. Factors affecting the caffeine and polyphenol contents of black and green tea infusions. J Agric Food Chem 2003;49 Suppl 11:5340-7.

3. Song W, Zhu XF, Ding XD, Yang HB, Qin ST, Chen $\mathrm{H}$, et al. Structural features, antioxidant and tyrosinase inhibitory activities of proanthocyanidins in leaves of two tea cultivars. Int J Food Prop 2017;20 Suppl 6:1348-58.

4. Suganuma M, Takahashi A, Watanabe T, Iida K, Matsuzaki T, Yoshikawa HY, et al. Biophysical approach to mechanisms of cancer prevention and treatment with green tea catechins. Molecules 2016;21:1566

5. Wiseman SA, Balentine DA, Frei B. Antioxidants in tea. Crit Rev Food Sci Nutr 1997;37:705-18.

6. Graham HN. Green tea composition, consumption, and polyphenol chemistry. Prev Med 1992;21:334-50.

7. Rabeta MS, Vithyia M. Effect of different drying methods on the antioxidant properties of Vitex negundo Linn. Tea. Int Food Res J 2013;20 Suppl 6:3171-6.

8. Sunarto PA. Pengawasan Obat dan Makanan, Penerbit Ditektorat Jenderal. Jakarta: Materia Medika Indonesia; 1977.

9. Ismail M, Manickam E, Danial AM, Rahmat A, Yahaya A. Chemical composition and antioxidant activity of Strobilanthes crispus leaf extract. J Nutr Biochem 2000;11 Suppl 11:536-42.

10. Nurraihana H, Norfarizan-Hanoon NA. Phytochemistry, pharmacology and toxicology properties of Strobilanthes crispus. Int Food Res J 2013;20 Suppl 5:2045-56.

11. Mohd-Fadzelly AB, Arnida HT, Asmah R, Fauziah O, Normah H, Sharida F. Antiproliferative properties and antioxidant activity of various types of Strobilanthes crispus tea. Int J Cancer Res 2006;2 Suppl 2:152-8.

12. Nurshaira CK. Antibacterial Activity of Methanolic Crude Ethanol Extracts from Selected Plant Against Bacillus cereus. Vol. 2. Selected Articles from the $7^{\text {th }}$ National Genetics Congress; 2007. p. 175-83.

13. Rasmussen W, Rhinehart R. Tea Basics: A Quick and Easy Guide. New York: John Sons, Inc.;1999.

14. Hamrouni-Sellami I, Rahali FZ, Rebey IB, Bourgou S, Limam F, Marzouk B. Total phenolics, flavonoids, and antioxidant activity of sage (Salvia officinalis L.) plants as affected by different drying methods. Food Bioprocess Technol 2013;6 Suppl 3:806-17.

15. Capecka E, Marecczek A, Leja M. Antioxidant activity of fresh and dry herbs of some Lamiaceae species. Food Chem 2005;93:223-6.

16. Sathishkumar R, Lakshmi PT, Annamalai A. Effect of drying treatment on the content of antioxidants in Enicostem malittorale Blume. Res $\mathrm{J}$ Med Plant 2009;3 Suppl 3:93-101.

17. Kuljarachanan T, Devahastin S, Chiewchan N. Evolution of antioxidant compounds in lime residues during drying. Food Chem 2009;113:944-9.

18. Chantaro P, Devahastin S, Chiewchan N. Production of antioxidant high dietary fiber powder from carrot peels. Lebenson Wiss Technol 2008;41:1987-94

19. Choi Y, Lee SM, Chun J, Lee HB, Lee J. Influence of heat treatment on the antioxidant activities and polyphenolic compounds of shitake (Lentinus edodes) mushroom. Food Chem 2006;99:381-7.

20. Park YS, Jung ST, Kang SG, Licon ED, Ayala AL, Tapia MS. Drying of persimmons (Diospyros kaki L.) and the following changes in the studied bioactive compounds and the total radical scavenging activities. Lebenson Wiss Technol 2006;9:748-55

21. Ohlsson T, Bengtsson N. Microwave technology and foods. In: Talor S, editor. Advances in Food and Nutrition Research. New York: Academic Press; 2001. p. 65-140

22. Prakasah P, Jha SK, Datta N. Performance evalution of blanced carrot dried by three different driers. J Food Eng 2004;62:305-13.

23. Adisewojo RS. Bercocok Tanam Teh. Bandung: Sumur Bandung; 1982.

24. Gadow AV, Joubert E, Hansmann CF. Comparison of the antioxidant activity of rooibos tea (Aspalathus linearis) with green, oolong and black tea. Food Chem 1997;60:73-7.

25. Velioglu YS, Mazza G, Gao L, Oomah BD. Antioxidant activity and phenolics in selected fruits, vegetables and grain products. J Agric Food Chem 1998;46:4113-7.

26. Ling JY, Tang CY. Determination of total phenolic and flavonoid content in selected fruits and vegetables, as well their stimulatory effects on mouse splenocyte proliferation. Food Chem 2007;101:140-7.

27. Nurul SR, Asmah R. Evaluation of antioxidant properties in fresh and pickled papaya. Int Food Res J 2012;19 Suppl 3:1117-24.
28. Benzie IF, Strain JJ. Ferric reducing antioxidant power assay: Direct measure of total antioxidant activity of biological fluids and modified version for simultaneous measurement of total antioxidant power and ascorbic acid concentration. Methods Enzymol 1999;299:15-27.

29. Barek M, Hasmadi M, Zaleha AZ, Mohd Fadzelly AB. Effect of different drying methods on phytochemicals and antioxidant properties of unfermented and fermented teas from Sabah Snake Grass (Clinacanthus nutans Lind.) leaves. Int Food Res J 2015;22 Suppl 2:661-70.

30. Chan EW, Lim YY, Chew YL. Antioxidant activity of Camellia sinensis leaves and tea from a lowland plantation in Malaysia. Food Chem 2007:102 Suppl 4:1214-22.

31. Bhaigyabati T, Devi PG, Bag GC. Total flavonoid content and antioxidant activity of aqueous rhizome extract of three Hedychium species of Manipur valley. Res J Pharm Biol Chem Sci 2014;5 Suppl 5:970-6.

32. Anesini C, Ferraro GE, Filip R. Total polyphenol content and antioxidant capacity of commercially available tea (Camellia sinensis) in argentina. J Agric Food Chem 2008;56:9225-9.

33. Belitz HD, Grosch W, Schieberle PE. Food Chemistry. Germany: Springer-Verlag Berlin Heidelberg; 2009.

34. Robertson A. The Chemistry and Biochemistry of Black tea Productionthe Non-Volatiles in Tea. Netherlands: Springer; 1992.

35. Valadez-Carmona L, Cortez-García RM, Plazola-Jacinto CP, Necoechea-Mondragón H, Ortiz-Moreno A. Effect of microwave drying and oven drying on the water activity, color, phenolic compounds content and antioxidant activity of coconut husk (Cocosnucifera L.). J Food Sci Technol 2016;53 Suppl 9:3495-501.

36. Ibrahim GE, El-Ghorab AH, Osman F, El-Massry KF. Effect of microwave heating on flavour generation and food processing. The Development and Application of Microwave Heating. United Kingdom: In Tech;2012.

37. Chan EW, Lim YY, Wong SK, Lim KK, Tan SP, Lianto FS, et al. Effects of different drying methods on the antioxidant properties of leaves and tea of ginger species. Food Chem 2009;113 Suppl 1:166-72.

38. Seremet Ceclu L, Botez E, Nistor OV, Andronoiu DG, Mocanu GD. Effect of different drying methods on moisture ratio and rehydration of pumpkin slices. Food Chem 2016;195:104-9.

39. Roshanak S, Rahim MM, Goli SA. Evaluation of seven different drying treatments in respect to total flavonoid, phenolic, vitamin $\mathrm{C}$ content, chlorophyll, antioxidant activity and color of green tea (Camellia sinensis or C. Assamica) leaves. J Food Sci Technol 2016;53:721-9.

40. Miletić N, Mitrović O, Popović B, Nedović V, Zlatković B, Kandić M. Polyphenolic content and antioxidant capacity in fruits of plum (Prunusdomestica L.) cultivars "Valjevka" and "Mildora" as influenced by air drying. J Food Qual 2013;36 Suppl 4:229-37.

41. Peterson J, Dwyer J, Bhagwat S, Haytowitz D, Holden J, Eldridge AL, Aladesanmi J. Major flavonoids in dry tea. J Food Compos Anal 2005;18 Suppl 6:487-501.

42. Muslim NS, Ng KW, Itam A, Nassar ZD, Ismail Z, Abdul Majid AM. Evaluation of cytotoxic, anti-angiogenic and antioxidant properties of standardized extracts of Strobilanthes crispus leaves. Int J Pharm 2010;6:591-9

43. Suhaila WQ, Mahmood AA, Lee SC, Nigar N, Mazatulikhm MZ, Salehhuddin H. Antioxidant, total phenolic content, and cytotoxicity evalution of selected Malaysian plants. Molecules 2011;16:3433-43.

44. Chan EW, Lye PY, Eng SY, Tan YP. Antioxidant properties of herbs with enhancement effects of drying treatments: A synopsis. Free Radic Antioxid 2013;3 Suppl 1:2-6

45. Gould GW. New Methods of Food Preservation. Glasgow: Blackie Academic and Professional; 1995.

46. Gowen A, Abu-Ghannam N, Frias J, Oliveira J. Optimisation of dehydration and rehydration properties of cooked chickpeas (Cicerarietinum L.) undergoing microwave-hot air combination drying. Trends Food Sci Technol 2006;17 Suppl 4:177-83.

47. Inchuen S, Narkrugsa W, Pornchaloempong P. Effect of drying methods on chemical composition, color and antioxidant properties of Thai red curry powder. Kasetsart J Nat Sci 2010;44:142-15.

48. Vadivambal R, Jayas DS. Changes in quality of microwave-treated agricultural products-a review. Biosyst Eng 2007;98 Suppl 1:1-16.

49. Chong KL, Lim YY. Effects of drying on the antioxidant properties of herbal tea from selected Vitex species. J Food Qual 2012;35 Suppl 1:51-9.

50. Yen GC, Chen HY. Antioxidant activity of various tea extracts in relation to their antimutagenicity. J Agric Food Chem 1995;43 Suppl 1:27-32.

51. Hasmadi M, Barek M, Zaleha AZ, Mohd Fadzelly AB. Effect of different drying methods on phytochemicals and antioxidant properties of unfermented and fermented teas from Sabah Snake Grass (Clinacanthus nutans Lind.) leaves. Int Food Res J 2015;22 Suppl 2:661-70.

52. Kim Y, Goodner KL, Park JD, Choi J, Talcott, ST. Changes 
in antioxidant phytochemicals and volatile composition of Camellia sinensis by oxidation during tea fermentation. Food Chem 2011;129 Suppl 4:1331-42.

53. Huang D, Ou B, Prior RL. The chemistry behind antioxidant capacity assays. J Agric Food Chem 2005;53:1841-56.

54. Sudha, BR, Remakanthan A, Hareesh KH, Aryakrishna UK. A comparative study of the phytochemicals, antioxidant and antibacterial potential of methanolic extracts of Trichosanthes cucumerina (L.) Var. Cucumerina under in vitro culture and natural conditions. Int J Pharm Pharm Sci 2018;10 Suppl 1:147-54.

55. Nagat M, Barka E, Lawrence R, Saani M. Phytochemical screening, antioxidant and antibacterial activity of active compounds from Hemidesmus indicus. Int J Curr Pharm Res 2016;8:24-7.

56. Praveena B, Pradeep SN. Antioxidant and antibacterial activities in the leaf extracts of Indian borage (Plectran thusamboinicus). Food Nutri Sci 2012;3:146-52

57. Khoddami A, Wilkes MA, Roberts TH. Techniques for analysis of plant phenolic compounds. Molecules 2013;18:2328-75.

58. Heim KE, Tagliaferro AR, Bobilya DJ. Flavonoid antioxidants: Chemistry, metabolism and structure-activity relationships. J Nutri Biochem 2002;13 Suppl 10:572-84.

59. Mraihi F, Journi M, Chérif JK, Sokmen M, Sokmen A, TrabelsiAyadi M. Phenolic contents and antioxidant potential of Crataegus fruits grown in Tunisia as determined by DPPH, FRAP, and $\beta$-carotene/ linoleic acid assay. J Chem 2013;8:1-6.

60. Sunila A, Murugan K. Variation in phenolics, flavonoids at different stages of fruit development of Pouteria campechiana (Kunth) Baehni and its antioxidant activity. Int J Pharm Pharm Sci 2017;9 Suppl 10:70-5. 